\title{
STRATEGI PENGEMBANGAN SUMBER DAYA MANUSIA YANG BERDAYA SAING DAN BERKELANJUTAN PADA AGROINDUSTRI TEBU: TINJAUAN LITERATUR DAN AGENDA PENELITIAN MENDATANG
}

\section{COMPETITIVE AND SUSTAINABLE HUMAN RESOURCES DEVELOPMENT STRATEGY IN SUGARCANE AGROINDUSTRY: LITERATURE REVIEW AND FUTURE RESEARCH AGENDA}

\author{
Mursiti $^{1 *}$, Illah Sailah ${ }^{2)}$, Marimin $^{2)}$, Muhammad Romli' ${ }^{2)}$, Alex Denni ${ }^{3)}$ \\ ${ }^{1)}$ Kementerian Perindustrian, J1. Widya Chandra VIII No. 34, Jakarta 12950, Indonesia \\ *Email: mursiti.verde.9@ gmail.com \\ ${ }^{2}$ Departemen Teknologi Industri Pertanian, Institut Pertanian Bogor, Indonesia \\ ${ }^{3}$ Kementerian Badan Usaha Milik Negara, Jl. Medan Merdeka Selatan No. 13, Jakarta, Indonesia \\ Makalah: Diterima 1 Februari 2021; Diperbaiki 5 Juni 2021; Disetujui 30 Juni 2021
}

\begin{abstract}
The purpose of this paper was to analyze the sugarcane agroindustry situational, human resources, and regulations to obtain new research on sugarcane agroindustry. The method carried out was by collecting 50 articles from 2002 - 2020 from indexed journals, theses, books. Articles were divided into three parts, namely sugarcane agroindustry with 14 articles, human resources with 19 articles and 17 regulations. In the VUCA era, we need skills, systems thinking skills, predictive abilities, and the ability to change quickly which is coupled with the Covid-19 pandemic conditions that accelerate the need for digitalization in the VUCA era. The results of the analysis show that the problem of lagging human resources in Eastern Indonesia is caused by a mismatch between labour users' needs and the availability of skills. The non-oil and gas processing industry sector provide the largest contribution to employment, one of which is the sugarcane industry. The sugarcane agroindustry problem was the large gap between supply of 2.17 million tons and demand of 6.6 million tons of which the shortfall of 4.43 million tons is met through imports of raw crystal sugar. The government's efforts to suppress imports by encouraging the private sector to establish new sugar factories outside Java and the expansion of existing sugar factories are accompanied by the preparation of human resources, so that a strategy for developing human resources that is competitive and able to adapt to the environment is needed.
\end{abstract}

Keywords: eastern Indonesia, human resources, situational analysis, sugar cane agro-industry, strategy

\begin{abstract}
ABSTRAK
Tujuan tulisan ini adalah menganalisis situasional agroindustri gula tebu, sumber daya manusia, dan regulasi untuk memperoleh kebaruan penelitian pada agroindustri gula tebu. Metode dilakukan dengan mengumpulkan 50 artikel sejak tahun 2002 - 2020 dari jurnal terindeks, tesis/disertasi, buku. Artikel dibagi 3 bagian yaitu agroindustri tebu 14 artikel, SDM 19 artikel dan 17 regulasi. Di era VUCA, kita membutuhkan keterampilan, kemampuan berpikir sistem, kemampuan prediksi, dan kemampuan untuk berubah secara cepat yang ditambah lagi dengan kondisi pandemi Covid-19 yang mempercepat kebutuhan digitalisasi di era VUCA. Hasil analisis menunjukkan permasalahan ketertinggalan SDM di Kawasan Timur Indonesia (KTI) disebabkan karena kekurangcocokkan pengguna tenaga kerja antara kebutuhan dan ketersediaan keterampilan yang diperlukan. Sektor industri pengolahan non migas memberikan kontribusi terbesar dalam penyerapan tenaga kerja, salah satunya industri gula tebu. Permasalahan pada agroindustri gula tebu adalah kesenjangan yang cukup besar antara penawaran sebesar 2,17 juta ton dan permintaan sebesar 6,6 juta ton yang kekurangannya sebesar 4,43 juta ton dipenuhi melalui impor gula kristal mentah. Upaya pemerintah untuk menekan impor dengan mendorong pihak swasta untuk mendirikan pabrik gula baru di luar Jawa dan ekstensifikasi pabrik gula yang ada dengan disertai penyiapan SDM, sehingga diperlukan strategi pengembangan SDM yang berdaya saing serta mampu beradaptasi di lingkungan.
\end{abstract}

Kata kunci: analisis situasional, sumber daya manusia, kawasan timur indonesia, agroindustri gula tebu, strategi

\section{PENDAHULUAN}

Era global dan disruptive mengakibatkan korporasi menghadapi kompetisi ketat yang disebut VUCA (Volatility, Uncertainty, Complexity, and
Ambiguity). Artinya, entitas bisnis sudah tidak bisa menggunakan pola bisnis lama dalam melakukan kegiatan bisnisnya. VUCA berkaitan dengan cara seseorang dalam melihat kondisi baik saat merencanakan, membuat keputusan, mengelola suatu 
resiko, dan memecahkan permasalahan. Di era VUCA, kita membutuhkan keterampilan, kemampuan berpikir sistem, kemampuan prediksi, dan kemampuan untuk berubah secara cepat (Nasution et al., 2020). Kita tidak akan dapat bertahan berjuang dan mengalami kegagalan dalam menghadapi VUCA apabila tidak memiliki keterampilan tersebut.

Ditambah lagi dengan adanya pandemi Covid19 yang mempercepat kebutuhan digitalisasi di era VUCA ini. Cepatnya virus Covid-19 bermutasi, membuat banyak perubahan-perubahan bisnis model yang dulunya tidak terbayangkan akan terjadi begitu cepat. Dengan demikian, strategi semakin dibutuhkan dan menjadi semakin penting saat persaingan semakin ketat dan perubahan lingkungan bisnis semakin VUCA. Di masa lalu, persaingan hanya sebatas pada perebutan sumber daya alam, tetapi di era sekarang, perebutannya melebar ke penguasaan platform dan SDM (Nasution et al., 2020).

Indonesia memiliki populasi sekitar 270,20 juta yang merupakan sebuah kekuatan besar untuk mendukung akselerasi pertumbuhan ekonomi, kesejahteraan, dan kemajuan bersama (BPS, 2020). Tren demografi global diperkirakan bahwa penduduk dunia menjadi 9,45 miliar (Asia 55\%) mendorong urbanisasi, arus migrasi, dan penduduk usia lanjut (Bappenas, 2019). Pada tahun 2010 - 2045, proporsi penduduk produktif Indonesia sering disebut dengan bonus demografi. Profil tingkat pendidikan berdasarkan data BPS (2020) bahwa tingkat pendidikan tenaga kerja Indonesia masih didominasi jenjang pendidikan dasar sebesar 52,3 juta orang (37,9\%); pendidikan menengah pertama sebesar 24,7 juta orang $(17,9 \%)$; sedangkan pendidikan menengah atas sebesar 25,7 juta orang $(18,7 \%)$; pendidikan menengah kejuruan sebesar 16,9 juta orang (12,3\%); pendidikan akademi (DI/II/III) sebesar 3,9 juta orang $(2,8 \%)$; dan pendidikan universitas sebesar 14,2 juta orang $(10,3 \%)$ dari total 137.906 .008 orang. Artinya tenaga kerja Indonesia didominasi oleh tenaga kerja yang kurang terampil sebesar 55,8\%.

Saat ini, kita sedang berada di era Revolusi Industri 4,0, dimana teknologi telah menyatu dengan masyarakat dan tubuh manusia. Penguasaan iptek dan inovasi sejalan dengan industri 4,0 menjadi kunci daya saing global suatu bangsa di masa depan. Tantangan pengembangan SDM di masa industri 4,0 mengakibatkan jabatan pekerjaan digantikan oleh mesin canggih dan jabatan pekerjaan juga akan menggunakan otomatisasi. Akibat dampak ini, maka pekerja memerlukan keterampilan ulang dan atau mengganti keterampilan.

Sektor industri pengolahan nonmigas memberikan kontribusi terbesar terhadap pertumbuhan ekonomi nasional dan menjadi sektor unggulan nasional. Pengembangan industri nasional tahun 2020-2024 diarahkan pada implementasi Making Indonesia 4.0 lebih di fokuskan pada 5 sektor industri, yaitu: (1) industri makanan dan minuman;
(2) industri tekstil dan busana; (3) industri otomotif; (4) industri kimia; dan (5) industri elektronika (Bappenas, 2020). Tren otomasi ke depan merupakan kesempatan untuk meningkatkan produktivitas.

Pemerintah Indonesia mengklasifikasikan tujuh komoditas pangan strategis, yaitu padi, tebu, jagung, kedelai, unggas, cabai, dan daging sapi (Kementerian Pertanian, 2020). Kementerian Perindustrian mencatat produksi gula putih berbasis tebu pada 2018 sebesar 2,17 juta ton. Sementara, kebutuhan gula nasional mencapai 6,6 juta ton. Berarti terjadi kesenjangan antara permintaan dan penawaran berdasarkan data tren produksi dan konsumsi gula nasional, kekurangan tersebut dipenuhi melalui impor gula kristal mentah (Perindustrian et al., 2020). Saat ini, produksi gula nasional dipasok oleh 48 pabrik gula milik Badan Usaha Milik Negara (BUMN) dan 17 pabrik gula milik swasta. Untuk menekan volume impor, pemerintah berupaya memacu tumbuhnya pabrikpabrik gula baru di luar Jawa dan perluasan pabrik gula yang sudah ada (Kementerian Perindustrian RI 2015). Dalam upaya peningkatan produksi gula, pemerintah tidak hanya bergantung pada peran pabrik gula atau off farm, melainkan juga peran dari sisi petani tebu.

Upaya pemerintah untuk pemenuhan kebutuhan gula dibuka lebar-lebar kepada pihak swasta untuk mendirikan pabrik gula. Terdapat pabrik gula atau sebut saja PT. XYZ yang merupakan pabrik gula di Indonesia Timur yang memiliki nilai investasi sebesar Rp1,3 triliun sekaligus menghasilkan produk sampingan berupa bio-ethanol, pupuk organik dan pakan ternak. Pabrik ini dapat menyerap tenaga kerja untuk sektor inti sekitar 500 orang dan sektor penunjang bisa mencapai sekitar 3.000 orang. Mayoritas karyawan perusahaan merupakan tenaga lokal sekitar, artinya pabrik gula ini mampu menciptakan lapangan kerja bagi masyarakat lokal. Tidak hanya itu, kehadiran pabrik gula juga memberikan multiplier effect bagi warga sekitar.

Keterbatasan tenaga kerja sekitar dengan kebutuhan pabrik gula memerlukan perbaikan, mulai dari on farm dan off farm. Secara umum, tenaga kerja yang ada sekarang memiliki kemampuan hard skill dan soft skill masih memiliki kesenjangan yang cukup besar apabila dibandingkan dengan sumber daya manusia yang ada di pulau Jawa berdasarkan hasil observasi peneliti saat dilakukan rekrutmen. Kondisi ini merupakan potret bahwa Indonesia memiliki ketertinggalan kompetensi SDM di Kawasan Timur indonesia (KTI), dimana SDM di Kawasan Barat Indonesia (KBI) dianggap memiliki kompetensi yang lebih baik (Enny, 2000). Tentunya perlu strategi pengembangan SDM yang dihubungkan dengan era digitalisasi di tengah pandemi covid-19 dimana pemerintah mendorong kepada pihak swasta untuk berinvestasi mendirikan pabrik gula di luar Jawa karena memiliki dampak signifikan pada penciptaan 
lapangan kerja, penyerapan tenaga kerja serta pemerataan pembangunan yang dapat mengurangi kesenjangan kompetensi SDM di KTI. Perlu komitmen berbagai pihak baik pemerintah, industri dan lembaga pendidikan untuk mengembangkan kompetensi SDM di era industri 4,0 pada pabrik gula. Berdasarkan kondisi tersebut penulis tertarik untuk melakukan penelitian, dengan memberikan alternatif rekomendasi skenario kebijakan untuk pengembangan SDM yang berdaya saing dan berkelanjutan pada agroindustri gula tebu. Untuk itu, pada tulisan ini peneliti akan melakukan tinjauan literatur yang mendukung tujuan penelitian berupa alternatif rekomendasi skenario kebijakan pengembangan SDM yang berdaya saing dan berkelanjutan pada agroindustri gula tebu.

\section{METODE PENELITIAN}

Artikel yang dijadikan referensi berjumlah 50 artikel, sejak tahun 2002 - 2020 diterbitkan dari jurnal nasional, internasional terindeks terkemuka, tesis/disertasi, buku. Kualifikasi jurnal dalam skripsi ini terbagi menjadi 3 bagian yaitu agroindustri tebu sebanyak 14 artikel, SDM artikel 19 artikel dan regulasi 17 artikel yang dapat dilihat pada Tabel 1 .

Tabel 1. Kualifikasi jurnal dan penulis berdasarkan tiga perspektif

\begin{tabular}{|c|c|c|}
\hline Kualifikasi & Deskripsi & Penulis \\
\hline $\begin{array}{l}\text { Perspektif } \\
\text { agroindustri } \\
\text { tebu }\end{array}$ & $\begin{array}{l}\text { Perkembangan agroindustri } \text { tebu, } \\
\text { permasalahan yang dihadapi dan solusi yang } \\
\text { telah diterapkan untuk dijadikan literatur serta } \\
\text { potensi pengembangan agroindustri } \\
\text { kedepannya. }\end{array}$ & $\begin{array}{ll}\text { 1. } & \text { (Asrol, 2021) } \\
\text { 2. } & \text { (Hernández-Pérez et al., 2020) } \\
\text { 3. } & \text { (Miranda } \text { et al., 2020) } \\
\text { 4. } & \text { (Silalertruksa } \text { et al., 2020) } \\
\text { 5. } & \text { (Ate } \text { et al., 2016) } \\
\text { 6. } & \text { (Siahaan, 2016) } \\
\text { 7. } & \text { (Mahbubi ,2015) } \\
\text { 8. } & \text { (Hartanto, 2014) } \\
\text { 9. } & \text { (Furtado } \text { et al., 2011) } \\
\text { 10. } & \text { (Putra dan Suryani,2 014) } \\
\text { 11. } & \text { (Subiyanto, 2013) } \\
\text { 12. } & \text { (Suripto, 2013) } \\
\text { 13. } & \text { (Dibyoseputro, 2012) } \\
\text { 14. } & \text { (Wahyuni, 2009) }\end{array}$ \\
\hline Perspektif SDM & $\begin{array}{l}\text { Perkembangan sumber daya manusia, } \\
\text { permasalahan yang dihadapi dan solusi yang } \\
\text { diterapkan dapat dijadikan serta potensi } \\
\text { pengembangan sumber daya manusia di masa } \\
\text { depan. }\end{array}$ & $\begin{array}{l}\text { 1. } \quad \text { (Bizzi, 2020) } \\
\text { 2. (De Prins } \text { et al., 2020) } \\
\text { 3. (Faller } \text { et al., 2020) } \\
\text { 4. (Fareri } \text { et al., 2020) } \\
\text { 5. (Morrison } \text { et al., 2020) } \\
\text { 6. (Urbancová dan Vrabcová, 2020) } \\
\text { 7. (Yusuf Enoch, 2020) } \\
\text { 8. (Cassar } \text { et al. ,2018) } \\
\text { 9. (Fadhil } \text { et al., 2017) } \\
\text { 10. (Fajri, 2018) } \\
\text { 11. (Nurbiyati, 2017) } \\
\text { 12. (Strietska-ilina et al., 2016) } \\
\text { 13. (Reio } \text { et al., 2015) } \\
\text { 14. (Jiang } \text { et al., 2012) } \\
\text { 15. (Chermack } \text { et al., 2010) } \\
\text { 16. (Garavan, 2007) } \\
\text { 17. (Becker dan Huselid, 2006) } \\
\text { 18. (Chermack, 2003) } \\
\text { 19. (Church } \text { et al., 2002) }\end{array}$ \\
\hline $\begin{array}{l}\text { Perspektif } \\
\text { Regulasi }\end{array}$ & $\begin{array}{l}\text { Regulasi yang berhubungan dengan } \\
\text { pengembangan SDM dan industri agroindustri } \\
\text { gula tebu yang dapat dijadikan sebagai }\end{array}$ & $\begin{array}{ll}\text { 1. } & \text { (Keuangan et al., 2020) } \\
\text { 2. } & \text { (Perindustrian, 2020) } \\
\text { 3. } & \text { (Keuangan } \text { et al., 2020) } \\
\text { 4. } & \text { (Ketenagakerjaan, 2020) }\end{array}$ \\
\hline
\end{tabular}




\begin{tabular}{lll}
\hline Kualifikasi & Deskripsi & Penulis \\
\hline alternatif kebijakan pengembangan SDM ke & 5. (Keuangan, 2019) \\
depan yang lebih baik lagi. & 6. (Perindustrian, 2017) \\
& 7. (Kementerian Ketenagakerjaan, 2016) \\
& 8. (Ketenagakerjaan, 2016) \\
9. (Peraturan Pemerintah RI, 2015) \\
10. (Perdagangan, 2015) \\
11. (Kementerian Perindustrian RI, 2015) \\
12. (Indonesia, 2014) \\
13. (RI, 2012) \\
14. (Nasional, 2010) \\
15. (Hidup, 2010) \\
16. (Peraturan Pemerintah RI, 2006) \\
17. (Indonesia, 2003)
\end{tabular}

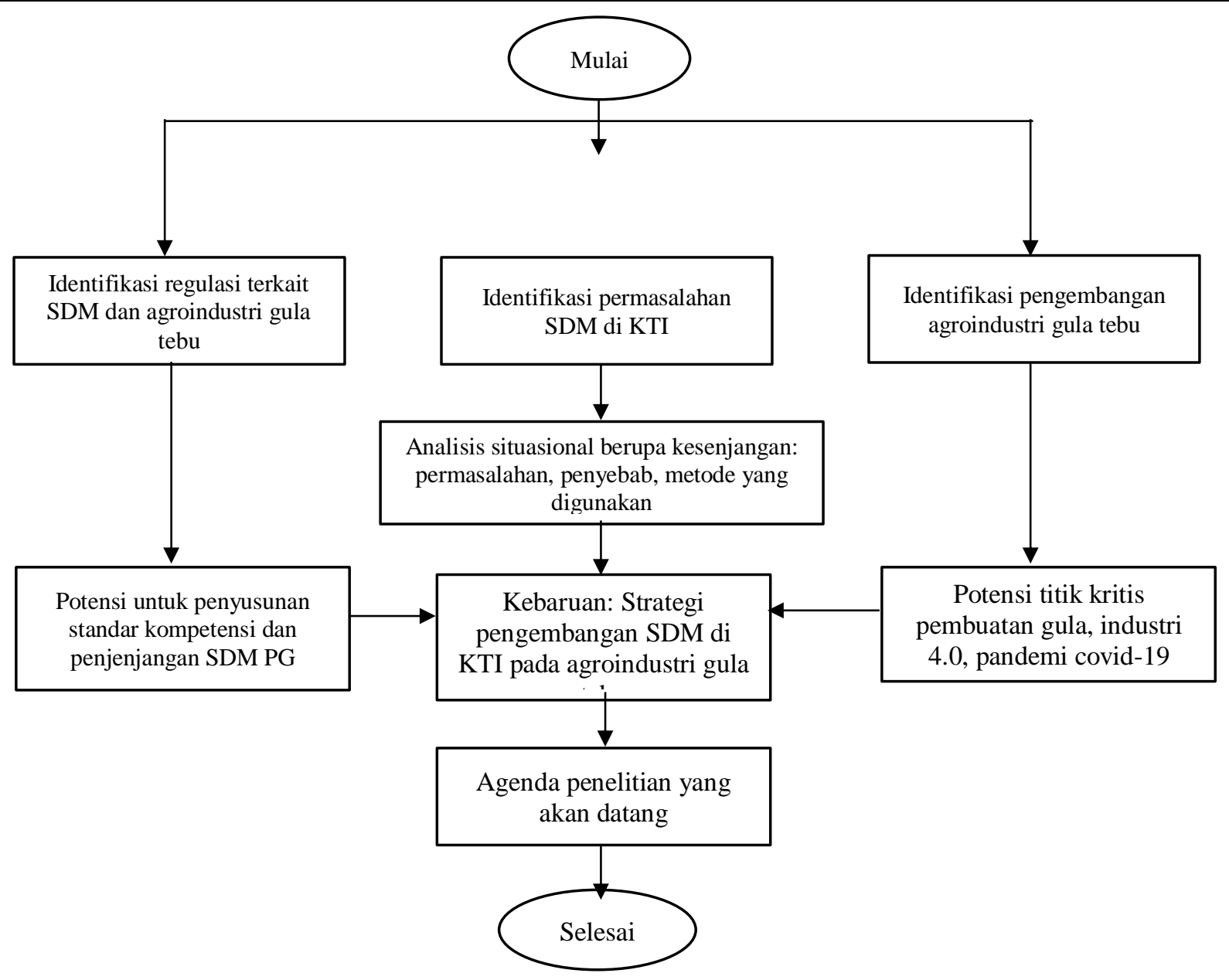

Gambar 1. Metode studi literatur

\section{Metode}

Gambar 1 menunjukkan metode mengenai proses mendapatkan potensi kebaruan penelitian pada agroindustri gula tebu dengan menelusuri literatur dari 3 perspektif yaitu agroindustri gula tebu, sumber daya manusia dan regulasi sehingga diperoleh analisis situasional berdasarkan literatur. Kemudian dilakukan analisa dengan mengkolaborasi literatur yang diperoleh untuk mendapatkan potensi kebaruan penelitian selanjutnya.

\section{Perspektif Agroindustri Gula Tebu}

Dibyoseputro (2012) menyatakan bahwa agroindustri gula tebu memiliki peluang menumbuhkan peluang penciptaan tenaga kerja, pertumbuhan ekonomi yang tersebar di berbagai kawasan serta peluang pertumbuhan industri 
pendukung lain. Pemasok utama agroindustri gula tebu terdiri dari petani tebu rakyat, pabrik gula dan distributor. Peluang agroindustri ini masih belum dapat terealisasi yang dibuktikan dengan adanya kekurangan antara jumlah penawaran dan permintaan produk gula. Swasembada gula merupakan hal yang diharapkan dapat terjadi. Faktor pendorong mencapai swasembada gula yang diusulkan yaitu perlu peningkatan TCD (ton cane day), rendemen, dan luas lahan (Ate et al., 2016). Penerapan mekanisasi para petani tebu akan membawa pengaruh terhadap keberhasilan penanaman tebu. Manajemen mekanisasi pertanaman tebu yang tepat akan membuat penggunaan alat mekanisasi menjadi efektif dan efisien (Siahaan, 2016). Putra et al. (2014) menunjukkan variabel yang mempengaruhi persediaan gula yaitu produktivitas lahan, lahan baru, intensifikasi lahan dan produksi gula. Selain itu, agroindustri gula tebu juga memiliki banyak potensi yang dapat dikembangkan. Hal ini dapat terlihat dari pohon industri tebu yang menghasilkan berbagai produk samping.

\section{HASIL DAN PEMBAHASAN}

\section{Perspektif Agroindustri Gula Tebu}

Dibyoseputro (2012) menyatakan bahwa agroindustri gula tebu memiliki peluang menumbuhkan peluang penciptaan tenaga kerja, pertumbuhan ekonomi yang tersebar di berbagai kawasan serta peluang pertumbuhan industri pendukung lain. Pemasok utama agroindustri gula tebu terdiri dari petani tebu rakyat, pabrik gula dan distributor. Peluang agroindustri ini masih belum dapat terealisasi yang dibuktikan dengan adanya kekurangan antara jumlah penawaran dan permintaan produk gula. Swasembada gula merupakan hal yang diharapkan dapat terjadi. Faktor pendorong mencapai swasembada gula yang diusulkan yaitu perlu peningkatan TCD (ton cane day), rendemen, dan luas lahan (Ate et al., 2016). Penerapan mekanisasi para petani tebu akan membawa pengaruh terhadap keberhasilan penanaman tebu. Manajemen mekanisasi pertanaman tebu yang tepat akan membuat penggunaan alat mekanisasi menjadi efektif dan efisien (Siahaan, 2016). Putra et al. (2014) menunjukkan variabel yang mempengaruhi persediaan gula yaitu produktivitas lahan, lahan baru, intensifikasi lahan dan produksi gula. Selain itu, agroindustri gula tebu juga memiliki banyak potensi yang dapat dikembangkan. Hal ini dapat terlihat dari pohon industri tebu yang menghasilkan berbagai produk samping.

Inovasi pada agroindustri gula tebu diperlukan dimulai dari perkebunan, pengolahan dan limbah tebu itu sendiri. Beberapa penelitian pada agroindustri tebu seperti yang dilakukan oleh Hartanto (2014) menunjukkan bahwa teknologi pembuatan gula menggunakan teknologi defekasi remelt karbonatasi (DRK) dapat memperbaiki kualitas gula dibandingkan dengan teknologi sulfitasi melalui perbandingan berbagai parameter seperti warna kristal, warna larutan, kadar belerang dioksida $\left(\mathrm{SO}_{2}\right)$ yang relatif rendah. Selanjutnya, Subiyanto (2013) menyatakan bahwa untuk melakukan migrasi teknologi sistem sulfitasi ke defekasi remelt karbonatasi (DRK) sebaiknya dimulai dari PG yang mempunyai cadangan ampas berlebih.

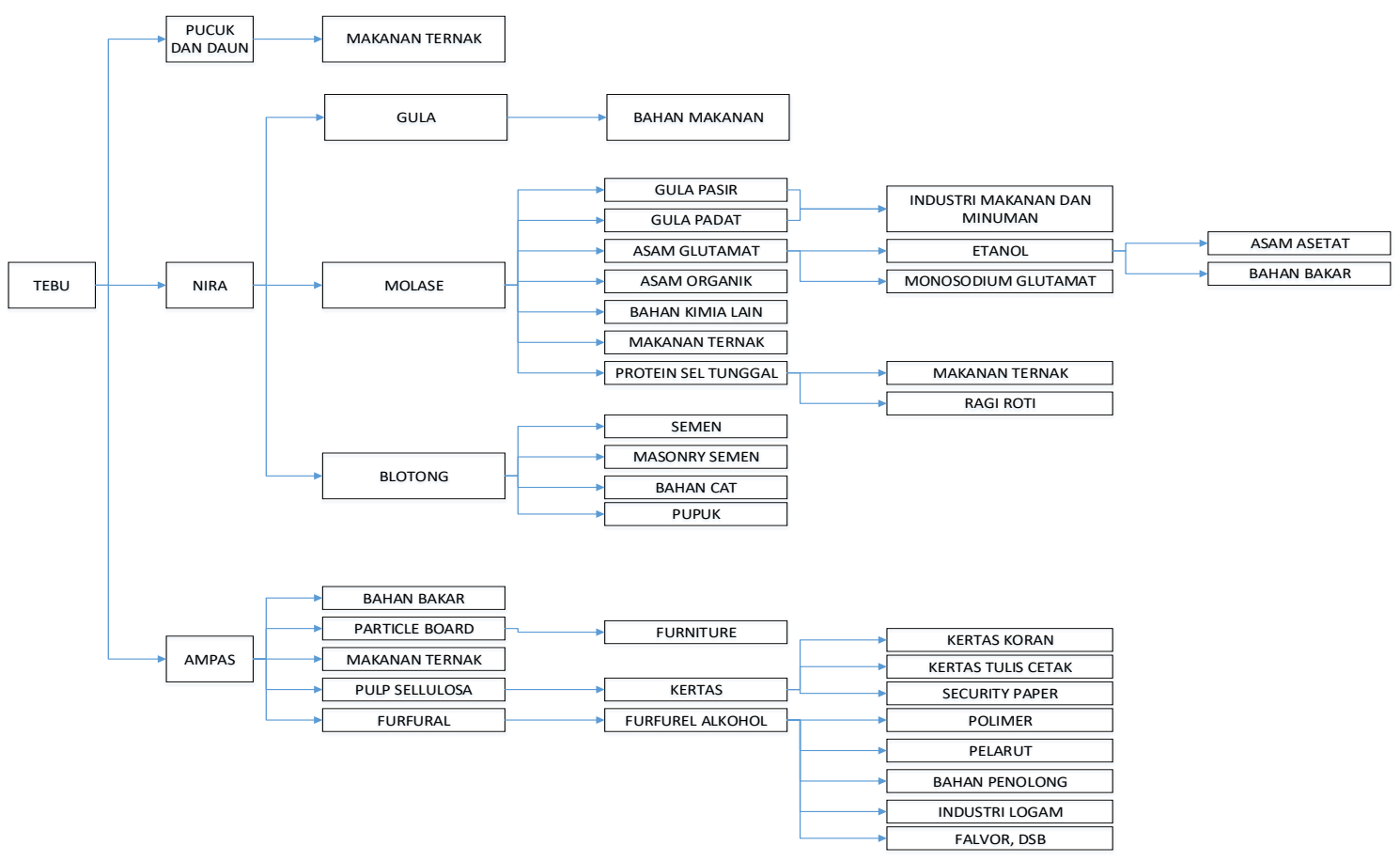

Gambar 2. Pohon industri tebu 
Penelitian Hernández-Pérez et al. (2020) meneliti sirup tebu sebagai suplemen nutrisi meningkatkan produksi xylitol dari campuran ampas tebu dan jerami, menjadi alternatif untuk mengurangi biaya dalam formulasi media fermentasi dan berkontribusi pada integrasi bioproses pada biorefinery. Penelitian Silalertruksa dan Gheewala (2020) meneliti biorefineri PLA (Polylactid Acid) berbasis tebu menjadi pilihan apabila gula-listriketanol yang ada menghadapi ketidakpastian. Miranda et al. (2020) meneliti pirolisis yang dapat diterapkan pada pilot plant serta untuk berbagai jenis proses dengan potensi besar untuk produksi biochar dan biominyak selain produksi gas yang tinggi. Asrol (2021) merancang model penyeimbangan risiko dan nilai tambah agar diperoleh rantai pasok yang berkeadilan dan berkelanjutan. Wahyuni (2009) menganalisa sejarah agroindustri gula, hal-hal yang yang dapat dipetik antara lain: (1) Kejayaan gula pada zaman penjajahan; (2) Dukungan dana yang kuat; (3) Kelembagaan dan sumberdaya manusia Indonesia belum siap untuk mengembangkan pergulaan; (4) Kebijakan kurang komprehensif. Suripto (2013) mengidentifikasi 9 tindakan penanganan risiko prioritas. Fahrizal (2015) menyatakan bahwa pengembangan agroindustri gula tebu di Nusa Tenggara Timur bertujuan dominan untuk pada penyerapan tenaga kerja. (Cahyani, 2017) mengusulkan strategi produktivitas bagi hasil yaitu pengelolaan lahan tebu yang terintegrasi dengan pengelolaan pabrik dan sistem beli. Inovasi agroindustri tebu memerlukan keterlibatan berbagai pihak seperti lembaga riset, kebijakan, strategi inovasi para pemain utama di sektor tebu termasuk pabrik gula, pemasok barang industri, lembaga penelitian baik publik dan swasta dan pemerintah (Furtado et al., 2011). Berdasarkan literatur ini, semua stakeholders harus berperan aktif serta harus membuat roadmap industrialisasi gula (Mahbubi, 2015).

Tinjauan di atas menunjukkan agroindustri gula memiliki potensi untuk dikembangkan di Indonesia berdasarkan sejarah dimana Indonesia pernah mengalami kejayaan. Peluang pengembangan sekaligus mengurangi impor melalui upaya swasembada. Faktor-faktor yang mempengaruhi swasembada gula yaitu perlu peningkatan TCD (ton cane day), rendemen, lahan baru, intensifikasi lahan, mekanisasi pertanaman tebu, produktivitas lahan, dan produksi gula. Selain itu, potensi tebu yang menghasilkan berbagai produk samping menunjukkan inovasi turut berperan memberikan kontribusi dalam peningkatan nilai tambah tebu melalui penelitian baik dari aspek teknologi, metode, proses, lingkungan ekosistem, rantai pasok yang satu sama lain saling berhubungan. Stakeholder terkait diharapkan berperan aktif baik lembaga riset, kebijakan, strategi inovasi para pemain utama di sektor tebu termasuk pabrik gula, pemasok barang industri, lembaga penelitian baik publik dan swasta dan pemerintah. Terlihat masih banyak yang bisa diteliti dari agroindustri gula tebu, untuk itu peneliti akan mengambil salah satu faktor yaitu peningkatan TCD sesuai dengan peran tempat kerja peneliti di Badan Pengembangan Sumber Daya Manusia Industri di Kementerian Perindustrian.

\section{Perspektif Sumber Daya Manusia}

Enny (2000) menggambarkan potret ketertinggalan SDM di Kawasan Timur Indonesia (KTI) bahwa permasalahannya adalah rendahnya kualitas dan kapabilitas SDM. Masalah krusial yang dihadapi KTI yaitu semakin banyaknya jumlah penggangguran akibat ketidakseimbangan antara persediaan tenaga kerja dengan kebutuhan tenaga kerja. Penyebab ketidakseimbangan adalah ketidak cocokkan antara keinginan atau kebutuhan dengan pengguna tenaga kerja atau kurang memenuhi persyaratan seperti keterampilan, pendidikan, keahlian, dan pengalaman kerja. Fenomena lainnya, penduduk di KTI dengan pendidikan SD kebawah ternyata tingkat penggangguran lebih rendah daripada pendidikan SMA sederajat keatas. Gambaran ini menunjukkan penduduk yang berpendidikan rendah berpartisipasi cukup tinggi dalam perekonomian KTI. Selain itu, fenomena yang dialami oleh investor yang sulit mendapatkan tenaga kerja lokal yang siap pakai yang akhirnya diisi oleh tenaga kerja di luar KTI. Hal ini juga perlu mendapat perhatian dimana arus migran yang tinggi agar tidak menimbulkan potensi terjadinya diintegrasi antar etnis.

Definisi manajemen sumber daya manusia adalah pengakuan akan pentingnya tenaga kerja manusia sebagai sumber daya vital yang berkontribusi pada tujuan organisasi (Nurbiyati, 2017). Di era sekarang ini, tuntutan kinerja serta ruang, waktu dan sumber daya yang terbatas membuat karyawan perlu belajar sendiri. Industri 4,0 memperkenalkan perubahan dan tantangan yang cepat dan penting. Diantaranya, masalah keterampilan dan profil pekerjaan yang mengambil peran penting untuk mengelola tren digitalisasi dengan benar (Chiarello et al., 2018). Identifikasi teknologi saat ini dan yang akan datang dapat dijadikan alat untuk mengidentifikasi keterampilan di masa depan (Strietska-ilina et al., 2016). Profesional perlu diberikan pelatihan yang sesuai di bidang teknologi informatika serta kaitannya agar sepenuhnya memahami implikasi yang terlibat dalam penerapannya dan mengkomunikasikan masa depan kepada orang lain (Church et al., 2002). Beberapa penelitian menunjukkan tren cara-cara meningkatkan ketrampilan tenaga kerja seperti dialog sosial yang mampu memediasi hubungan antara iklim industri yang kooperatif dengan kerugian karyawan secara efisien (De Prins et al., 2020), keterlibatan karyawan dalam blogging dengan rekan kerja (Bizzi, 2020), mempertahankan karyawan kunci; meningkatkan motivasi; meningkatkan kinerja; dan memperbaiki iklim organisasi memiliki manfaat yang signifikan 
(Urbancová dan Vrabcová, 2020), praktik pembelajaran berbasis action learning (AL) agar karyawan menyesuaikan diri dalam lingkungan yang cepat berubah (Faller et al., 2020), kegiatan program pengembangan sumber daya manusia di suatu wilayah diformalkan untuk mengurangi ketegangan sosial (Yusuf Enoch, 2020), sistem pembelajaran dengan menghapal hendaknya jangan membatasi organisasi untuk beradaptasi (Morrison dan Kowalski 2020). Jiang et al. (2012) menunjukkan bahwa sistem SDM mempunyai hubungan sinergis diantara tiga komponen yaitu kebijakan SDM, kegiatan aditif, dan substitusi. Profil tenaga kerja milenial di era revolusi industri 4,0 yaitu memilih pekerjaan dengan jenjang karir yang jelas, kenyamanan lingkungan kerja terutama lingkungan kerja non fisik lebih disukai dari pada pekerjaan dengan gaji yang besar, lebih menyukai pekerjaan yang bebas tanpa aturan yang ketat dan lebih sedikit tekanan, memilih mengerjakan pekerjaan yang menjadi hobinya yang dapat menghasilkan uang dan dapat bermanfaat bagi orang lain, lebih suka bekerja dengan orang-orang yang mempunyai umur yang relatif sama dengan mereka (Fajri, 2018).

Investasi SDM merupakan investasi intelektual yang memiliki arti penting bagi pembangunan daerah (Fadhil et al., 2017). Diperlukan strategi pengembangan SDM merupakan rangkaian kegiatan pembelajaran dan pengembangan yang koheren berkontribusi pada pencapaian tujuan strategis. Pendekatan sistem terbuka memungkinkan pertimbangan berbagai faktor secara bersamaan berperan di perusahaan. Dimana diharapkan dapat membantu menciptakan kondisi dimana tujuan strategis dan kinerja yang dihasilkan dapat direalisasikan (Garavan, 2007). Perencanaan tenaga kerja berbasis skenario merupakan salah satu alat yang tersedia bagi organisasi untuk digunakan dalam perencanaan dan pengembangan tenaga kerja (Erdogan et al., 2009). Chermack et al. (2010) menggunakan dua alat utama yaitu perencanaan skenario dan kecakapan organisasi untuk meningkatkan efektivitas organisasi dengan fokus pada bagaimana tim dapat digunakan sebagai mode utama untuk mencapai tujuan. Metode lain yaitu penggunaan alat statistik diperlukan untuk analisis yang rinci (Reio et al., 2015). Selain itu, penelitian SDM juga perlu memasukkan logika penelitian akademis ke dalam pengambilan keputusan (Becker dan Huselid, 2006). Keahlian pengambilan keputusan dipandang sebagai inti untuk pengembangan dan optimalisasi keahlian manusia dalam organisasi (Chermack, 2003).

Tinjauan di atas menunjukkan permasalahan SDM di KTI yaitu kesenjangan antara ketersediaan dan kebutuhan akan persyaratan yang diinginkan oleh pengguna, rendahnya tingkat partisipasi dengan pendidikan tinggi dalam perekonomian, serta perlunya mengantisipasi arus migran yang tinggi agar tidak meninbulkan disintegrasi antar etnis. Tantangan lain yaitu berupa kondisi sekarang apalagi ditambah dengan pandemi covid-19 menuntut SDM dapat belajar sendiri, mampu mengidentifikasi teknologi saat ini dan masa depan, pelatihan teknologi informatika yang cocok. Literatur juga menunjukkan cara-caranya seperti dialog sosial dengan blogging, mempertahankan karyawan kunci, meningkatkan motivasi, kinerja dan iklim organisasi. Sehingga dapat menyesuaikan diri dalam lingkungan yang cepat berubah. Berbagai pendekatan dalam literatur yang dapat digunakan seperti perencanaan skenario, alat statistik sehingga mampu mengambil keputusan yang terbaik. Sehingga, pengembangan SDM di KTI ini merupakan upaya yang sangat strategis baik dari sisi pemerataan pembangunan, kesejahteraan dan pengurangan kesenjangan dengan Kawasan Barat Indonesia (KBI).

\section{Perspektif Regulasi}

Tinjauan regulasi dilakukan untuk mengetahui upaya yang telah dilakukan pemerintah dalam mendukung pengembangan agroindustri gula tebu serta penyiapan SDM. Di bidang agroindustri gula tebu, upaya pemerintah untuk pemenuhan kebutuhan gula nasional dilakukan dengan mengeluarkan ketentuan impor dengan persyaratan tertentu (Perdagangan, 2015), pemberian fasilitasi impor bahan baku gula kristal mentah untuk jangka waktu tertentu yaitu jangka waktu 7 (tujuh) tahun bagi perusahaan industri gula yang berada di luar Jawa dan 5 (lima) tahun bagi perusahaan industri gula di Jawa (Perindustrian, 2017). Selain itu, upaya pemerintah untuk menghasilkan produk yang bermutu dan aman dikonsumsi telah diatur oleh Badan Standarisasi Nasional mengenai gula kristal putih pada SNI 013140.3:2010 (Nasional, 2010). Pemerintah juga memperhatikan aspek keberlanjutan lingkungan ekosistem yang ramah lingkungan dan industri hijau yang diatur dalam Peraturan Menteri Perindustrian Republik Indonesia Nomor 9 Tahun 2020 Tentang Standar Industri Hijau Untuk Industri Gula Kristal Putih (2020), Peraturan Menteri Negara Lingkungan Hidup Nomor 05 Tahun 2010 Tentang Baku Mutu Air Limbah Bagi Industri Gula (2010).

Di bidang sumber daya manusia, Pemerintah membagi jenis-jenis SDM industri menjadi 4 (empat) yaitu wirausaha industri, tenaga kerja industri, pembina industri dan konsultan industri (UndangUndang Nomor 3 Tahun 2014 Tentang Perindustrian, 2014). Penelitian akan difokuskan pada tenaga kerja industri, dimana tenaga kerja industri terdiri dari tenaga teknis dan tenaga manajerial yang setidaknya memiliki kompetensi teknis sesuai dengan SKKNI di bidang industri dan pengetahuan manajerial (Peraturan Pemerintah RI, 2015). Definisi Standar Kompetensi Kerja Nasional Indonesia yang disingkat SKKNI adalah rumusan kemampuan kerja yang mencakup aspek pengetahuan, keterampilan dan/atau 
keahlian serta sikap kerja yang relevan dengan pelaksanaan tugas dan syarat jabatan yang ditetapkan sesuai dengan peraturan perundang-undangan (Kementerian Ketenagakerjaan 2016).

SKKNI akan menjadi acuan dalam penyusunan jenjang kualifikasi nasional, penyelenggaraan pendidikan dan pelatihan serta sertifikasi kompetensi. Pemerintah telah menerbitkan SKKNI bidang industri gula kristal rafinasi pada sub bidang quality control dan produksi (Ketenagakerjaan 2020). SKKNI ini dapat dijadikan referensi untuk menyusun standar kompetensi kerja khusus bidang industri gula tebu. Selanjutnya, penjenjangan SDM berdasarkan Kerangka Kualifikasi Nasional Indonesia terdiri dari 9 (Sembilan) jenjang kualifikasi, dimulai dari jenjang 1 (satu) sebagai jenjang terendah sampai dengan jenjang 9 (sembilan) sebagai jenjang tertinggi (RI 2012). SKKNI dan KKNI dapat dijadikan acuan untuk pendidikan dan pelatihan kerja. Pelatihan kerja adalah keseluruhan kegiatan untuk memberi, memperoleh, meningkatkan, serta mengembangkan kompetensi kerja, produktivitas, disiplin, sikap, dan etos kerja pada tingkat keterampilan dan keahlian tertentu sesuai dengan jenjang dan kualifikasi jabatan atau pekerjaan (Peraturan Pemerintah RI, 2006).

Selain itu, pemerintah juga mendorong investasi pada industri padat karya, mendukung program penciptaan lapangan kerja dan penyerapan tenaga kerja Indonesia, mendorong keterlibatan dunia usaha dan dunia industri dalam penyiapan sumber daya manusia yang berkualitas, dan meningkatkan daya saing, serta mendorong peran dunia usaha dan dunia industri melakukan penelitian dan pengembangan dengan memberikan fasilitas pembebasan atau pengurangan pajak penghasilan badan dan fasilitas pengurangan penghasilan neto dalam rangka penanaman modal serta pengurangan penghasilan bruto dalam kegiatan tertentu yang tertuang dalam Peraturan Pemerintah Nomor 45 Tahun 2019 Tentang Perubahan Atas Peraturan Pemerintah Nomor 94 Tahun 2010 Tentang Penghitungan Penghasilan Kena Pajak Dan Pelunasan Pajak Penghasilan Dalam Tahun Berjalan (2019), Peraturan Menteri Keuangan Republik Indonesia Nomor 153/PMK.010/2020 Tentang Pemberian Pengurangan Penghasilan Bruto Atas Kegiatan Penelitian Dan Pengembangan Tertentu Di Indonesia (2020), Peraturan Menteri Keuangan Republik Indonesia Nomor 128 /PMK.010/2019 Tentang Pemberian Pengurangan Penghasilan Bruto Atas Penyelenggaraan Kegiatan Praktik Kerja, Pemagangan, Dan/Atau Pembelajaran Dalam Rangka Pembinaan Dan Pengembangan Sumber Daya Manusia (2019).

Tinjauan di atas dihubungkan judul penelitian di atas menunjukkan belum ada yang regulasi mengenai standar kompetensi kerja di bidang agroindustri gula tebu serta penjenjangan SDM di pabrik gula yang akan dilakukan penelitian. Namun, secara umum pemerintah telah memfasilitasi industri untuk ikut mendukung mulai dari penciptaan lapangan kerja, penyerapan tenaga kerja industri dengan melibatkan dunia usaha dan dunia industri dalam penyiapan sumber daya manusia.

\section{Agenda Penelitian yang akan Datang Pada Agroindustri Gula Tebu}

Berdasarkan tinjauan literatur terhadap tiga perspektif yaitu agroindustri gula tebu, sumberdaya manusia, dan regulasi diperoleh kesenjangan yang kemudian dijadikan sebagai agenda penelitian yang akan datang pada agroindustri gula tebu. Pada perspektif agroindustri gula tebu, salah satu upaya untuk mengurangi masalah gula tebu yaitu impor gula mentah. Upaya pemerintah untuk mengurangi impor dilakukan dengan swasembada dimana salah satu faktor penting dalam swasembada gula tebu adalah dari sisi produksi gula. Kebijakan pendirian pabrik gula baru dan ekspansi pabrik gula yang sudah ada terutama yang berada di luar pulau Jawa akan didorong oleh pemerintah dan tentunya memerlukan dukungan SDM yang berdaya saing.

Pada perspektif SDM, permasalahan ketertinggalan SDM di KTI terjadi akibat ketidakseimbangan antara persediaan tenaga kerja dengan kebutuhan tenaga kerja disebabkan ketidak cocokkan antara keinginan atau kebutuhan dengan pengguna tenaga kerja atau kurang memenuhi persyaratan seperti keterampilan, pendidikan, keahlian, dan pengalaman kerja. Industri 4.0 memperkenalkan perubahan dan tantangan yang cepat dan penting. Ditambah lagi, Indonesia saat ini sedang mengalami pandemi covid-19 dan bonus demografi yang merupakan tantangan tersendiri agar dapat mengoptimal anugerah ini dengan kondisi yang sedang terjadi. Untuk itu, perlu strategi pengembangan SDM di KTI dengan kondisi tantangan industri 4.0, bonus demografi di tengahtengah pandemi covid-19 untuk penyiapan kualitas dan kapabilitas SDM yang berdaya saing. Strategi pengembangan SDM di KTI ini merupakan upaya yang sangat strategis baik dari sisi pemerataan pembangunan, kesejahteraan dan pengurangan kesenjangan dengan Kawasan Barat Indonesia (KBI).

Perspektif regulasi menunjukkan bahwa pemerintah telah menerbitkan Keputusan Menteri Ketenagakerjaan RI Nomor 178 Tahun 2020 tentang Penetapan SKKNI Kategori Industri Pengolahan Golongan Pokok Industri Makanan Bidang Industri Gula Kristal Rafinasi Pada Sub Bidang Quality Contro ( $Q C)$ dan Produksi dan belum ada yang regulasi mengenai standar kompetensi kerja di bidang agroindustri gula tebu serta penjenjangan SDM di pabrik gula. Namun, secara umum pemerintah telah memfasilitasi industri untuk ikut mendukung mulai dari penciptaan lapangan kerja, penyerapan tenaga kerja industri dengan melibatkan dunia usaha dan dunia industri dalam penyiapan sumber daya manusia. 
Tabel 2. Kebaruan Penelitian Dibandingkan Dengan Penelitian Sebelumnya Pada Agroindustri Gula Tebu di Indonesia

\begin{tabular}{|c|c|c|c|c|c|c|}
\hline No & Penulis & Judul & Objek & Metode & Permasalahan & Tujuan \\
\hline 1 & $\begin{array}{l}\text { (Dibyoseputro } \\
\text { 2012) }\end{array}$ & $\begin{array}{l}\text { Rancang Bangun } \\
\text { Sistem Dinamis } \\
\text { Pengambilan } \\
\text { Keputusan Kompleks } \\
\text { Pengembangan } \\
\text { Agroindustri Gula } \\
\text { Tebu. Bogor, } \\
\text { Indonesia. }\end{array}$ & $\begin{array}{l}\text { Pengembangan } \\
\text { Agroindustri Gula } \\
\text { Tebu di Bogor, } \\
\text { Indonesia }\end{array}$ & Sistem Dinamik & $\begin{array}{l}\text { Defisit pasokan belum } \\
\text { teratasi dengan baik dan } \\
\text { ketidaktepatan pelaksanaan } \\
\text { kebijakan importasi gula } \\
\text { yang dilakukan pada saat } \\
\text { tingkat persediaan gula } \\
\text { dalam negeri masih tinggi } \\
\text { dan mencukupi. }\end{array}$ & $\begin{array}{l}\text { Merancang bangun sebuah model } \\
\text { yang berbasis sistem dinamis untuk } \\
\text { membantu pengambilan keputusan } \\
\text { kompleks dalam rangka } \\
\text { pengembangan agroindustri gula } \\
\text { tebu. }\end{array}$ \\
\hline 2 & (Suripto 2013) & $\begin{array}{l}\text { Rancang Bangun } \\
\text { Model Manajemen } \\
\text { Resiko Agroindustri } \\
\text { Gula Tebu }\end{array}$ & Manajemen Resiko & Sistem Dinamik & $\begin{array}{l}\text { Pada skala pabrik } \\
\text { produktivitas dan efesiensi } \\
\text { yang rendah terjadi karena } \\
\text { berbagai risiko yang terjadi } \\
\text { dalam proses produksi gula } \\
\text { tebu yang belum teratasi } \\
\text { dengan baik. }\end{array}$ & $\begin{array}{l}\text { 1.Melakukan identifikasi risiko, } \\
\text { penilaian dan analisis risiko } \\
\text { agroindustri gula tebu serta } \\
\text { menentukan risiko prioritas } \\
\text { 2. Memformulasikan penanganan } \\
\text { risiko prioritas } \\
\text { 3. Merancang model simulasi } \\
\text { penanganan risiko agroindustri gula } \\
\text { tebu dengan pendekatan dinamika } \\
\text { sistem } \\
\text { 4. Merekomendasikan kebijakan } \\
\text { penanganan risiko agroindustri } \\
\text { gula tebu }\end{array}$ \\
\hline 3 & (Subiyanto 2013) & $\begin{array}{l}\text { Kelayakan Tekno- } \\
\text { Ekonomi Migrasi } \\
\text { Teknologi Proses } \\
\text { Produksi Gula Kristal } \\
\text { Putih Dari Sulfitasi Ke } \\
\text { Defekasi Remelt } \\
\text { Karbonatasi }\end{array}$ & $\begin{array}{l}\text { Kelayakan Tekno } \\
\text { Ekonomi Dari } \\
\text { Sulfitasi Ke } \\
\text { Defekasi Remelt } \\
\text { Karbonatasi }\end{array}$ & $\begin{array}{l}\text { Analisis kelayakan } \\
\text { melalui pendekatan: } \\
\text { (a) teknologi, (b) } \\
\text { ekonomi \& bisnis, dan } \\
\text { (c) persyaratan } \\
\text { penerapan. }\end{array}$ & $\begin{array}{l}\text { Mutu gula yang diproduksi } \\
\text { oleh pabrik milik negara } \\
\text { semakin terpuruk dengan } \\
\text { salah satu penyebabnya } \\
\text { adalah adopsi teknologi } \\
\text { proses yang kurang baik, } \\
\text { yang sebagian besar } \\
\text { menggunakan teknologi } \\
\text { sulfitasi. }\end{array}$ & $\begin{array}{l}\text { Mengevaluasi apakah investasi } \\
\text { perubahan tersebut mampu } \\
\text { memberikan nilai output yang } \\
\text { secara bisnis menguntungkan. }\end{array}$ \\
\hline 4 & $\begin{array}{l}\text { (Putra dan } \\
\text { Suryani 2014) }\end{array}$ & $\begin{array}{l}\text { Skenario Kebijakan } \\
\text { Industri Gula Untuk } \\
\text { Meningkatkan }\end{array}$ & $\begin{array}{l}\text { Ketersediaan Gula } \\
\text { di Pasaran }\end{array}$ & Sistem Dinamik & $\begin{array}{l}\text { Luas lahan tebu makin } \\
\text { berkurang yang berimbas }\end{array}$ & $\begin{array}{l}\text { Penelitian ini berfokus pada jumlah } \\
\text { persediaan gula Jawa Timur dimana } \\
\text { variabel yang mempengaruhinya }\end{array}$ \\
\hline
\end{tabular}




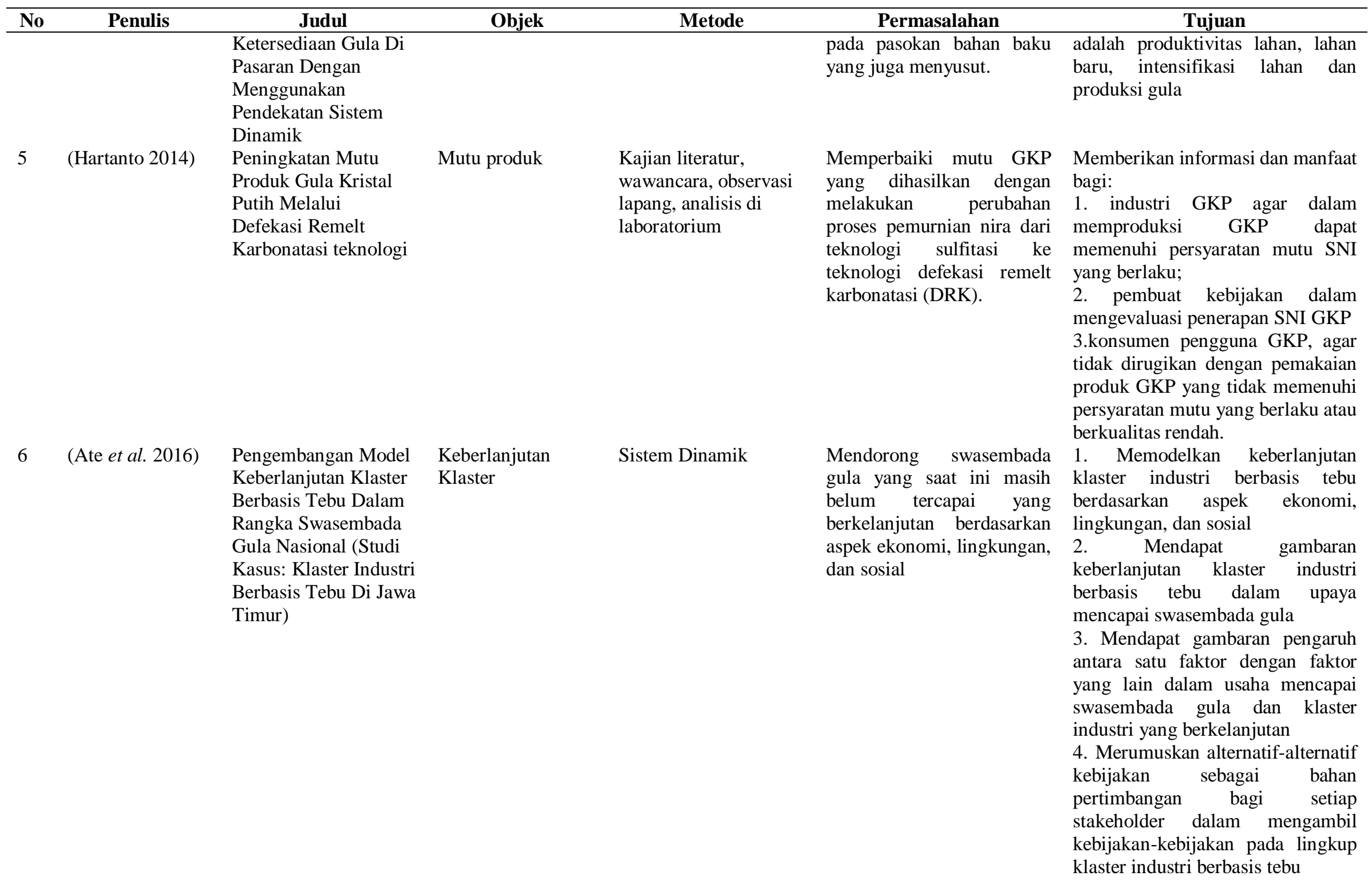




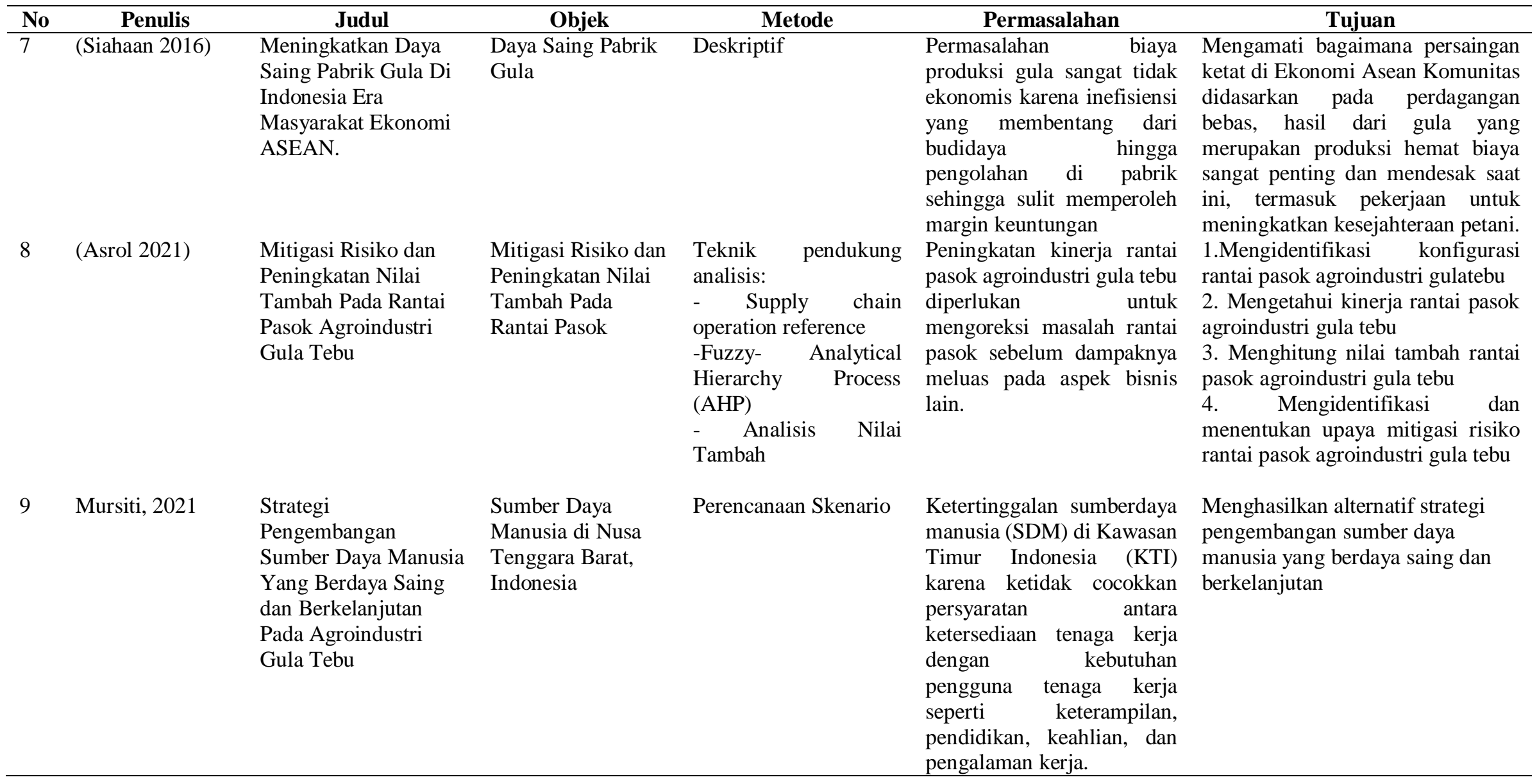


Berdasarkan literatur yang telah dilakukan, agenda penelitian yang akan dilakukan dengan mempertimbangkan permasalahan ketertinggalan SDM di KTI dengan berbagai tantangan yang dihadapi seperti dorongan agar industri menuju industri 4.0, ditambah lagi dengan pandemi covid-19 yang sedang terjadi serta memanfaatkan secara optimal bonus demografi yang sedang terjadi di negara kita Indonesia. Penyiapan SDM merupakan upaya yang perlu melibatkan banyak pihak karena bersifat nasional yang memerlukan dukungan terutama pemerintah sebagai regulator yang dapat menggerakkan stakeholder terkait dengan objek penelitian pada agroindustri gula tebu. Sehingga, peneliti tertarik untuk melakukan penelitian mengenai strategi pengembangan sumber daya manusia yang berdaya saing pada agroindustri gula tebu.

Kontribusi penelitian pada agroindustri gula tebu selanjutnya menghasilkan strategi pengembangan SDM di Kawasan Timur Indonesia dengan permasalahan SDM pada agroindustri gula tebu yang dapat dilihat secara terperinci pada Tabel 2 .

\section{KESIMPULAN DAN SARAN}

\section{Kesimpulan}

Peluang pengembangan sekaligus mengurangi impor melalui upaya swasembada. Selain itu, potensi tebu yang menghasilkan berbagai produk samping menunjukkan inovasi turut berperan memberikan kontribusi dalam peningkatan nilai tambah. Stakeholder terkait diharapkan berperan aktif baik lembaga riset, kebijakan, strategi inovasi para pemain utama di sektor tebu termasuk pabrik gula, pemasok barang industri, lembaga penelitian baik public dan swasta dan pemerintah. Permasalahan SDM di KTI yaitu kesenjangan antara ketersediaan dan kebutuhan akan persyaratan yang diinginkan oleh pengguna, rendahnya tingkat partisipasi dengan pendidikan tinggi dalam perekonomian, serta perlunya mengantisipasi arus migran. Peningkatan TCD melalui pendirian pabrik gula baru dan ektensifikasi pabrik gula yang sudah ada menjadi fokus pada pengembangan SDM di KTI yang sesuai dengan peran tempat kerja peneliti di Badan Pengembangan Sumber Daya Manusia Industri di Kementerian Perindustrian.

Artikel yang dijadikan referensi berjumlah 50 artikel sejak 2002 - 2020 diterbitkan dari jurnal nasional, internasional terindeks terkemuka, tesis/disertasi, buku dengan kualifikasi jurnal dalam skripsi ini terbagi menjadi 3 bagian yaitu agroindustri tebu sebanyak 14 artikel, artikel SDM 19 artikel dan regulasi sebanyak 17 regulasi. Penelitian sebelumnya menunjukkan bahwa belum ada penelitian yang meneliti pengembangan SDM di KTI pada agroindustri gula tebu belum ada.

\section{Saran}

Penelitian selanjutnya yang disarankan untuk melengkapi penelitian ini adalah dengan memasukkan aspek pendidikan baik Pendidikan formal maupun Pendidikan non-formal.

\section{UCAPAN TERIMA KASIH}

Penelitian didanai oleh Badan Pengembangan Sumber Daya Manusia Industri Kementerian Perindustrian. Kami mengucapkan terima kasih kepada pembimbing dari IPB dan di luar IPB yang telah memberikan masukan konstruktif untuk memperkaya makalah ini

\section{DAFTAR PUSTAKA}

Asrol M, Marimin, Machfud, Yani M. 2021. Risk Management for Improving Supply Chain Performance of Sugarcane Agroindustry. Industrial Engineering Management System. 20(1):9-26. doi.org/10.7232/iems.2021.20.1.9.

Ate BD. 2016. Pengembangan Model Keberlanjutan Rangka Swasembada Gula Nasional (Studi Kasus : Klaster Industri Berbasis Tebu Di Jawa Timur ). [Tesis]. Surabaya: Institut Teknologi Sepuluh Nopember.

Bappenas. 2020. Lampiran I Perpres No 18 Tahun 2020 Tentang Rencana Pembangunan Jangka Menengah Nasional Tahun 2020-2024.hlm 20.

Becker BE, Huselid MA. 2006. Strategic human resources management: Where do we go from here? Journal Management. 32(6):898-925. doi:10.1177/0149206306293668.

Bizzi L. 2020. Should HR managers allow employees to use social media at work? Behavioral and motivational outcomes of employee blogging. International Journal Human Resource Management. 31(10):1285-1312. doi:10.1080/09585192.2017.1402359.

Badan Standarisasi Nasional. SNI 3140.3:2010 Gula Kristal - Bagian 3 : Putih. 2010.

Badan Pusat Statistik--270-20-juta-PendudukIndonesia-Hasil-SP2020. 2020.

Cahyani. 2017. Model Produktivitas Bagi Hasil Agroindustri Gula Tebu Dalam Kemitraan Antara Petani Dan Perusahaan: Studi Kasus Di Pg Kremboong, Sidoarjo. Jurnal Teknologi Industri Pertanian. 27(2):114-124. doi:10.24961/j.tek.ind.pert.2017.27.2.114.

Cassar V, Tracz-Krupa K, Bezzina F, Przytuła S. 2018. "The Times They Are-a-Changin": Reconstructing the New Role of the Strategic Hr Manager. Management Science. 23(3):3-11. doi:10.15611/ms.2018.3.01.

Chermack TJ. 2003. Decision-Making Expertise at the Core of Human Resource Development. Advances in Developing Human Resources. 
$5(4): 365-377$.

doi: $10.1177 / 1523422303257283$.

Chermack TJ, Bodwell W, Glick M. 2010. Two strategies for leveraging teams toward organizational effectiveness: Scenario planning and organizational ambidexterity. Advances in Developing Human Resources. 12(1):137-156. doi:10.1177/1523422310365669.

Church AH, Gilbert M, Oliver DH, Paquet K, Surface C. 2002. The Role of Technology in Organization Development and Change. Advances in Developing Human Resources. 4(4):493-511. doi:10.1177/152342202237525.

Dibyoseputro MAB. 2012. Rancang bangun sistem dinamis pengambilan keputusan kompleks pengembangan agroindustri gula tebu. [Disertasi]. Bogor: Institut Pertanian Bogor.

De Prins P, Stuer D, Gielens T. 2020. Revitalizing social dialogue in the workplace: the impact of a cooperative industrial relations climate and sustainable HR practices on reducing employee harm. The International Journal Human Resource Management. 31(13):1684-1704. doi:10.1080/09585192.2017.1423098.

Erdogan B, Abbott C, Aouad G, Kazi AS. 2009. Construction it in 2030: A scenario planning approach. Journal of Information Technology in Construction. 14 August:540-555.

Fadhil R, Maarif MS, Bantacut T, Hermawan A. 2017. Model Strategi Pengembangan Sumber Daya Manusia Agroindustri Kopi Gayo dalam Menghadapi Masyarakat Ekonomi ASEAN. Jurnal Manajemen Teknologi. 16(2):141-155. doi:10.12695/jmt.2017.16.2.3.

Fahrizal. 2015. Model perencanaan agroindustri gula tebu lahan kering berkelanjutan di provinsi Nusa Tenggara Timur. [Disertasi]. Bogor: Institut Pertanian Bogor.

Fajri DK. 2018. Profil Tenaga Kerja Milenial di Indonesia pada Era Revolusi Industri 4 . 0. Di dalam: Festival Riset Ilmiah Manajemen dan Akuntasi. hlm 409-412.

Faller P, Marsick V, Russell C. 2020. Adapting Action Learning Strategies to Operationalize Reflection in the Workplace. Advances in Developing Human Resource. 22(3):291-307. doi: $10.1177 / 1523422320927298$.

Fareri S, Fantoni G, Chiarello F, Coli E, Binda A. 2020. Estimating Industry 4.0 impact on job profiles and skills using text mining. Computers in Industry. 118:103222. doi:10.1016/j.compind.2020.103222.

Furtado AT, Scandiffio MIG, Cortez LAB. 2011. The Brazilian sugarcane innovation system. Energy Policy. 39(1):156-166. doi:10.1016/j.enpol.2010.09.023.

Garavan TN. 2007. A Strategic Perspective on Human Resource Development. Advances in
Developing Human Resource. 9(1):11-30. doi:10.1177/1523422306294492.

Hartanto ES. 2014. Peningkatan Mutu Produk Gula Kristal Putih Melalui Teknologi Defekasi Remelt Karbonatasi. Jurnal Standarisasi. 16(3):215. doi:10.31153/js.v16i3.197.

Hernández-Pérez AF, Chaves-Villamil AC, de Arruda PV, dos Santos JC, Felipe M das G de A. 2020. Sugarcane Syrup Improves Xylitol Bioproduction from Sugarcane Bagasse and Straw Hemicellulosic Hydrolysate. Waste and Biomass Valorization. 11(8):4215-4224. doi:10.1007/s12649-019-00742-6.

Jiang K, Lepak DP, Han K, Hong Y, Kim A, Winkler AL. 2012. Clarifying the construct of human resource systems: Relating human resource management to employee performance. Human Resource Management Review. 22(2):73-85. doi:10.1016/j.hrmr.2011.11.005.

Keputusan Menteri Pertanian Nomor: 259/Kpts/RC.020/M/05/2020 Tentang Rencana Strategis Kementerian Pertanian Tahun 20202024. 2020.

Keputusan Menteri Ketenagakerjaan RI No 178 Tahun 2020 Tentang Penetapan SKKNI Kategori Industri Pengolahan Golongan Pokok Industri Makanan Bidang Industri Gula Kristal Rafinasi. 2020.

Mahbubi A. 2015. Sistem Dinamis Rantai Pasok Industrialisasi Gula. Agriekonomika. 4(2):198 209.

Miranda NT, Dianin LM, Fernandes DS, Filho RMI, MacIel MRW. 2020. Experimental study on sugarcane bagasse pyrolysis in a thermochemical processes pilot plant. Chemical Engineering Transaction. 80 February:37-42. doi:10.3303/CET2080007.

Morrison EA, Kowalski R. 2020. Postscript: How We Learn Is How We SEE. Advances in Developing Human Resource. 22(3):333-343. doi:10.1177/1523422320927301.

Nasution AH, Tjahjono B, Soewardjono D. 2020. Manajemen Strategi _ Pendekatan Change Management Berbasis Revo 4.0 di Era VUCA. PT PTS Tekno Sains.

Nurbiyati T. 2017. Evaluasi Pengembangan Sumber Daya Manusia: Sebuah Review. Kaji Bisnis STIE Widya Wiwaha. 23(1):52-63. doi:10.32477/jkb.v23i1.203.

Peraturan Menteri Ketenagakerjaan Republik Indonesia Nomor 3 Tahun 2016 Tentang Tata Cara Penetapan Standar Kompetensi Kerja Nasional Indonesia. 2016.

Peraturan Menteri Keuangan Republik Indonesia Nomor 128 /PMK.010/2019 Tentang Pemberian Pengurangan Penghasilan Bruto Atas Penyelenggaraan Kegiatan Praktik Kerja, Pemagangan, Dan/Atau Pembelajaran Dalam 
Rangka Pembinaan Dan Pengembangan Sumber Daya Manusia. 2019.

Peraturan Menteri Keuangan Republik Indonesia Nomor 153/PMK.010/2020 Tentang Pemberian Pengurangan Penghasilan Bruto Atas Kegiatan Penelitian Dan Pengembangan Tertentu Di Indonesia. 2020.

Peraturan Menteri Ketenagakerjaan Republik Indonesia Nomor 2 Tahun 2016 Tentang Sistem Standarisasi Kompetensi Kerja Nasional. 2016.

Peraturan Pemerintah Republik Indonesia Nomor 14 Tahun 2015 Tentang Rencana Induk Pembangunan Industri Nasional 2015 - 2035. 2015

Peraturan Menteri Negara Lingkungan Hidup Nomor 05 Tahun 2010 Tentang Baku Mutu Air Limbah Bagi Industri Gula. 2010.

Peraturan Pemerintah Republik Indonesia Nomor 31 Tahun 2006 Tentang Sistem Pelatihan Kerja Nasional. 2006.

Peraturan Pemerintah Republik Indonesia Nomor 41 Tahun 2015 Tentang Pembangunan Sumber Daya Industri.hlm 1-32. 2015.

Peraturan Pemerintah Nomor 45 Tahun 2019 Tentang Perubahan Atas Peraturan Pemerintah Nomor 94 Tahun 2010 Tentang Penghitungan Penghasilan Kena Pajak dan Pelunasan Pajak Penghasilan Dalam Tahun Berjalan. 2019.

Peraturan Menteri Perdagangan Nomor 117 tahun 2015 tentang Ketentuan Impor Gula.

Peraturan Menteri Perindustrian Nomor 10 Tahun 2017 Tentang Fasilitas Memperoleh Bahan Baku Dalam Rangka Pembangunan Industri Gula. 2015.

Peraturan Menteri Perindustrian Republik Indonesia Nomor 9 Tahun 2020 Tentang Standar Industri Hijau Untuk Industri Gula Kristal Putih. 2020.

Peraturan Presiden Republik Indonesia Nomor 8 Tahun 2012 Tentang Kerangka Kualifikasi Nasional Indonesia. 2012.

Putra AB, Suryani E. 2014. Skenario Kebijakan Industri Gula Untuk Meningkatkan Ketersediaan Gula Dipasaran Dengan Menggunakan Pendekatan Sistem Dinamik. Jurnal Sistem Informasi. 5(1):51-61. doi:10.24089/j.sisfo.2014.03.013.
Reio TG, Nimon K, Shuck B. 2015. Preface: Quantitative Data-Analytic Techniques to Advance HRD Theory and Practice. Advances in Developing Human Resource. 17(1):3-11. doi:10.1177/1523422314559653.

Siahaan M. 2016. "Meningkatkan Daya Saing Sektor Riel Di Era Masyarakat Ekonomi Asean." Jurnal Riset Ekonomi dan Manajemen. 16(2):275. doi:10.17970/jrem.16.160208.id.

Silalertruksa T, Gheewala SH. 2020. Competitive use of sugarcane for food, fuel, and biochemical through the environmental and economic factors. The International Journal of Life Cycle Assessment. 25(7):1343-1355. doi:10.1007/s11367-019-01664-0.

Strietska-ilina O, Hofmann C, Khachatryan L. 2016. Skills Technology Foresight Guide.

Subiyanto S. 2013. Kelayakan Tekno-Ekonomi Migrasi Teknologi Proses Produksi Gula Kristal Putih Dari Sulfitasi Ke Defekasi Remelt Karbonatasi. Jurnal Sains dan Teknologi Indonesia. 14(1):56-61. doi:10.29122/jsti.v14i1.906.

Suripto. 2013. Rancang Bangun Model Manajemen Risiko. [Disertasi]. Bogor. Institut Pertanian Bogor

Urbancová H, Vrabcová P. 2020. Age management as a human resources management strategy with a focus on the primary sector of the Czech Republic. Agricultural Economics (Zemédělská Ekon. 66 No. 6:251-259. doi:10.17221/11/2020-agricecon.

Undang-Undang Republik Indonesia Nomor 13 Tahun 2003 Tentang Ketenagakerjaan. 2003.

Undang-Undang Nomor 3 Tahun 2014 Tentang Perindustrian. 2014.

Wahyuni S. 2009. Industri dan perdagangan gula di Indonesia : pembelajaran dari kebijakan zaman penjajahan - sekarang. Jurnal Sistem Informasi. September:133-149.

Yusuf Enoch DH. 2020. Analysis of the efficiency of the regional human resources management program. Applied Sciences Review. 1:24-51. doi: 10.37686/nsr.v1i.72. 
Mursiti, Illah Sailah, Marimin, Muhammad Romli, Alex Denni 